\title{
REVIEW
}

\section{Pulmonary vascular disorders in portal hypertension}

\author{
P. Hervé*, D. Lebrec*, F. Brenot*†, G. Simonneau*, M. Humbert*, O. Sitbon*, P. Duroux*
}

\begin{abstract}
Pulmonary vascular disorders in portal hypertension. P. Hervé, D. Lebrec, F. Brenot, G. Simonneau, M. Humbert, O. Sitbon, P. Duroux. CERS Journals Ltd 1998.

ABSTRACT: The wide spectrum of pulmonary vascular disorders in liver disease and portal hypertension ranges from the hepatopulmonary syndrome characterized by intrapulmonary vascular dilatations, to pulmonary hypertension (portopulmonary hypertension), in which pulmonary vascular resistance is elevated. Since hepatopulmonary syndrome and portopulmonary hypertension have been reported in patients with nonhepatic portal hypertension, the common factor that determines their development must be portal hypertension. The clinical presentations are very different, with gas exchange impairment in the hepatopulmonary syndrome and haemodynamic failure in portopulmonary hypertension. The severity of hepatopulmonary syndrome seems to parallel the severity of liver failure, whereas no simple relationship has been identified between hepatic impairment and the severity of portopulmonary hypertension. Resolution of hepatopulmonary syndrome is common after liver transplantation, which has an uncertain effect in portopulmonary hypertension. The pathophysiology of both syndromes may involve vasoactive mediators and angiogenic factors.
\end{abstract}

Eur Respir J 1998; 11: 1153-1166.

This review focuses on the pulmonary vascular complications of chronic liver failure and portal hypertension. The wide spectrum of pulmonary vascular disorders in liver disease and portal hypertension ranges from the hepatopulmonary syndrome (HPS), which is characterized by intrapulmonary vascular dilatations, to pulmonary hypertension (portopulmonary hypertension), in which pulmonary vascular resistance (PVR) is elevated. The exact pathophysiological mechanisms of these pulmonary vascular disorders are unknown. However, since HPS and portopulmonary hypertension have been reported in patients with nonhepatic portal hypertension, the factor that determines their development must be portal hypertension.

A brief review of the haemodynamic changes observed in cirrhosis with portal hypertension is summarized, and the clinical and experimental evidence suggesting that the liver exerts a critical influence on the regulation of pulmonary vascular tone and angiogenesis is described. Portopulmonary hypertension is then discussed, focusing in turn on its clinical presentations, management and potential mechanisms, and referring to our findings in $39 \mathrm{pa}-$ tients with portopulmonary hypertension and 140 patients with primary pulmonary hypertension $(\mathrm{PPH})$ admitted between 1986 and 1996 at Antoine Béclère Hospital. Finally, HPS will be examined, with a discussion of the mechanisms of hypoxaemia and intrapulmonary vascular dilatation, as well as its clinical presentation, diagnosis and treatment, with special attention to liver transplantation.

\author{
*Service de Pneumologie et Réanimation, \\ Hôpital Antoine Béclère, Clamart, France; \\ \#Laboratoire d'Hémodynamique Splanch- \\ nique et de Biologie Vasculaire (INS- \\ ERM), Hôpital Beaujon, Clichy, France. \\ †Deceased. \\ Correspondence: P. Hervé \\ Centre Chirurgical Marie-Lannelongue \\ 133 Avenue de la Résistance \\ 92350 Le Plessis Robinson \\ France \\ Fax: 33146303792 \\ Keywords: Cirrhosis \\ hepatopulmonary syndrome \\ hypoxaemia \\ portal hypertension \\ pulmonary hypertension
}

Received: June 161997

Accepted after revision January 311998

\section{Haemodynamics in cirrhosis with portal hypertension}

An understanding of pulmonary haemodynamics in liver disease with portal hypertension is important to a study of the pulmonary vascular disorders seen in this setting. A hyperdynamic circulatory state with high cardiac output, low systemic vascular resistance and low PVR is present in $30-50 \%$ of patients with cirrhosis and also in animal models of portal hypertension [1-4]. Compared with healthy subjects (fig. 1), patients with portal hypertension have a lower median PVR value with a

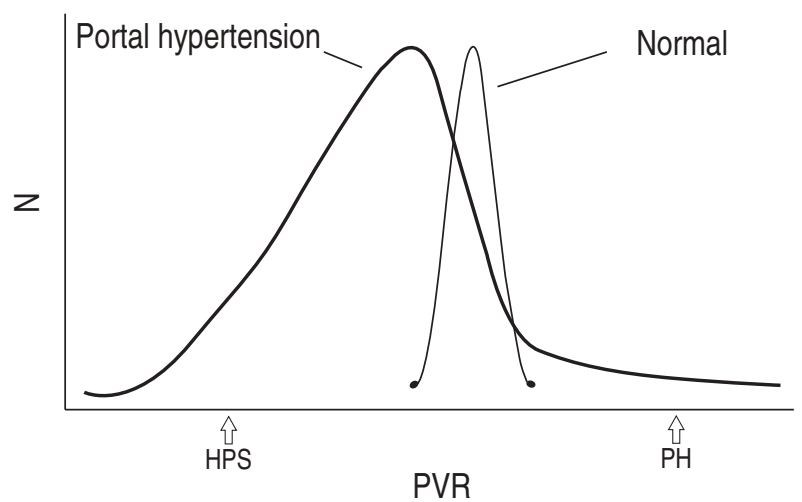

Fig. 1. - Schematic distribution of pulmonary vascular resistance (PVR) in patients with portal hypertension and in normal subjects (N). Compared with healthy subjects, patients with portal hypertension have a lower median PVR value (arrow) with a much wider range of PVR, extending from low levels consistent with the development of hepatopulmonary syndrome (HPS) to the high levels seen in portopulmonary hypertension $(\mathrm{PH})$ 
much wider range of PVR, extending from low levels consistent with the development of HPS to the high levels seen in portopulmonary hypertension [1]. In the studies by Hadengue et al. [1] and Campillo et al. [5], the Child- Pugh's score, which assesses the severity of cirrhosis, was positively correlated with the cardiac index.

Recent studies indicate that the systemic and pulmonary vasodilatation seen in cirrhosis and portal hypertension is a consequence of low vascular tone $[6,7]$, which results in turn in a decreased responsiveness to vasoconstrictors [8]. A decrease in hypoxic pulmonary vasoconstriction was found by NAEIJ et al. [9, 10] and MеLот et al. [11] in approximately $30 \%$ of patients with advanced cirrhosis. In a study by RodRIGUEZ-Roisin et al. [7], the group of cirrhotic patients with more severe liver failure had lower systemic and pulmonary vascular resistances, as well as less pulmonary vasoconstriction in response to hypoxia. LunZER et al. [12] and CAMPILLo et al. [6] found a decreased vasoconstrictor response to noradrenaline in the systemic vascular bed in patients with decompensated cirrhosis, contrasting with a normal vasoconstrictor res-ponse in patients with compensated cirrhosis [6]. All of these studies indicate that the decrease in both vascular tone and vascular responsiveness to exogenous vasoconstrictors is associated with the severity of the liver disease.

The pathogenesis of the hyperdynamic circulatory state seen in cirrhosis and portal hypertension is not well understood but may involve a combination of different factors [13], including an increase in sympathetic tone, high concentrations of circulating catecholamines, an increase in venous return due to portocaval anastomoses, and increases in various vasodilators and pro-inflammatory mediators [13]. These mediators include nitric oxide (NO), glucagon, calcitonin gene-related peptide, vasoactive intestinal peptide, atrial natriuretic factor, substance $\mathrm{P}$, interleukin (IL)-1, IL-6, tumour necrosis factor, platelet activating factor and leukotrienes (fig. 2).

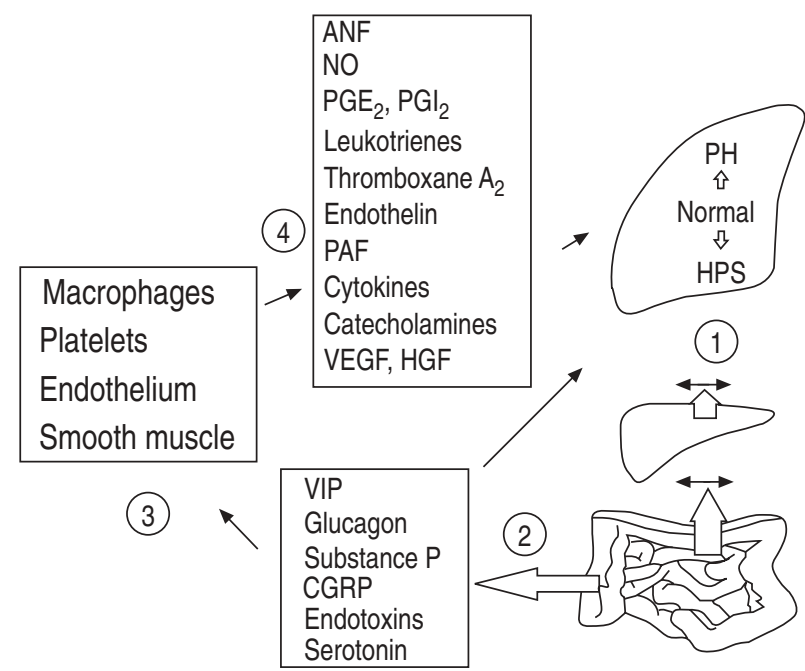

Fig. 2. - Schema of the relationships between the liver and the pulmonary circulation in the hepatopulmonary syndrome (HPS) and portopulmonary hypertension $(\mathrm{PH})$. Liver cirrhosis and portal hypertension results (1) in diversion of a normal venous hepatic blood flow from the pulmonary circulation, and may allow (2) substances normally cleared by the liver to gain access to the pulmonary circulation (VIP: vasointestinal peptide; CGRP: calcitonin gene-related peptide). Cirrhosis and portal hypertension indirectly or directly activate (3) various cells to induce the release (4) of numerous mediators (ANF: antinatriuretic factor; NO: nitric oxide; PG: prostaglandins; PAF: platelet activating factor; VEGF: vascular endothelial growth factor; HGF: hepatic growth factor).
The possibility that NO contributes to the hyperdynamic circulation seen in cirrhotic patients by mediating the decreases in vascular tone and reactivity has recently been proposed [14]. NO is believed to play a central role in the regulation of pulmonary and systemic vascular tone and vascular reactivity in humans [14]. In smooth muscle cells, NO binds to the haeme moiety of soluble guanylate cyclase, stimulating the formation of cyclic guanosine monophosphate and promoting smooth muscle relaxation [14]. NO is synthesized from L-arginine by a family of NO synthases (NOS). Three isoforms of NOS have been identified [14]. The two constitutive isoforms are expressed in neurons and endothelial cells (eNOS). The third form of NOS is not expressed in normal cells, but is induced by pro-inflammatory cytokines and endotoxin (iNOS) in endothelial and smooth muscle cells, as well as in monocytes and macrophages.

The production of NO is increased in advanced cirrhosis, but seems to be normal in compensated cirrhosis. Exhaled NO concentrations, which reflect NO production in the airways [15], are higher in advanced cirrhosis [1620] than in patients with compensated cirrhosis or in normal subjects. Moreover, patients with decompensated cirrhosis have higher serum levels of nitrites and nitrates $[5,20]$ than do patients with compensated cirrhosis and normal subjects. Lastly, a recent study [21] indicates enhanced endothelium-dependent vasodilatation of forearm resistance vessels in cirrhotic patients, which suggests an increased synthesis of NO in the vascular endothelium.

Whether increased production of NO accounts for the hyperdynamic circulation in humans however remains controversial. Some studies found that lung NO production was correlated with cardiac output [15, 20] or PVR [17], whereas others [5] failed to detect any relationship between serum and urinary nitrate levels and cardiac output. Moreover, cardiac output is increased in patients with compensated cirrhosis, a condition in which NO production is not different from normal. By contrast, the results of studies using inhibitors of NOS activity provide some support for the hypothesis that NO overproduction accounts for the decrease in vascular tone observed in advanced cirrhosis and portal hypertension. The effect on forearm blood flow of infusion into the brachial artery of noradrenaline and $\mathrm{NG}^{\mathrm{G}}$-monomethyl-L-arginine (L-NMMA), an inhibitor of NOS, was recently studied in decompensated [6] and compensated cirrhosis [22]. The vasoconstrictor response to noradrenaline and L-NMMA was similar in patients with compensated cirrhosis and in normal subjects [22]. However, the vasoconstrictor response to noradrenaline was decreased, and that to L-NMMA increased, in the decompensated group [6]. The effect of NOS inhibition on exhaled NO, pulmonary haemodynamics and pulmonary hypoxic vasoconstriction in patients with advanced cirrhosis remains unknown. Lastly, it remains to be determined in patients with cirrhosis whether increased production of NO is a consequence rather than a cause [14] of the hyperdynamic circulation, and may account for only part of the decrease in pulmonary and systemic vascular tone.

The increase in systemic and pulmonary production of NO could result from the overexpression or overstimulation of endothelial eNOS, from the induction of iNOS, or both. Vallance and Moncada [23] suggested that circulating endotoxin, which is elevated in cirrhotic patients, may induce iNOS expression in vascular walls, and that the 
resultant prolonged release of NO may lead to sustai-ned pulmonary and systemic vasodilation. However, a significant correlation between endotoxin levels and serum nitrates was found in only one [24] of three recent studies [5, 25]. LaFFy et al. [26] demonstrated that isolated leukocytes from patients with decompensated cirrhosis and hyperdynamic circulation produced more NO than those from healthy subjects. Interestingly, these patients had higher plasma endotoxin levels, suggesting that the expression of NOS by leukocytes may result from per- sistent endotoxin stimulation. However, some data in the literature suggest that human polymorphonuclear neutrophils express no iNOS but rather the constitutive form of NOS [24].

An alternative hypothesis [14] suggests that the increase in NO production may be due to the overexpression or overstimulation of the endothelial eNOS in response to factors that are increased in patients with advanced liver disease, such as shear stress, vasopressin, angiotensin II, noradrenaline and endothelin. Recent findings from experimental rat models of cirrhosis and portal hypertension support this hypothesis. Experimental models of cirrhosis in rats have been shown to reproduce reliably and consistently the pulmonary and systemic haemodynamic alterations observed in patients with cirrhosis and portal hypertension [27]. Rats with biliary cirrhosis exhibit decreased pulmonary and systemic vascular resistances, depressed hypoxic pulmonary vasoconstriction and increased NO production [27, 28]. Normalization of NO production with the NOS inhibitor L-nitro-arginine-methylester (LNAME) in cirrhotic rats with ascites corrected arterial vasodilatation and hyperdynamic circulation, whereas aortic concentration of guanosine 3',5'-cyclic monophosphate returned to normal values $[28,29]$. A recent study by Снавот et al. [30] found that the contractile response of isolated pulmonary artery rings to phenylephrine was reduced in rats with biliary cirrhosis, and that this reduction was abolished by pretreatment with the NOS inhibitor NWnitro-L-arginine (L-NA), suggesting that overproduction of $\mathrm{NO}$ was at least partly responsible for the low pulmonary vascular tone and decreased response to vasoconstrictor stimuli seen in the cirrhotic rats. There were no alterations, however, in pulmonary artery ring relaxation in response to the endothelium-dependent vasodilator acetylcholine (which stimulates endothelial eNOS), suggesting that NO overproduction was the result of iNOS induction rather than of endothelial eNOS overexpression. However, an increase in lung eNOS but not iNOS protein was found in the same rat model of biliary cirrhosis in a study by $\mathrm{F}_{\mathrm{AL}}-$ LoN et al. [31]. A similar decrease in the contractile response of aortic rings to phenylephrine was observed by WeIGERT et al. [32] in rats with tetrachloride-induced cirrhosis. This decrease was abolished by L-NAME, a nonselective NOS inhibitor, but not by aminoguanidine, a preferential iNOS inhibitor [32]. Again, aortic iNOS mRNA was undetectable [32], whereas enhanced eNOS mRNA abundance was found in the aorta [33]. Taken in concert, these findings do not support iNOS induction as the unique source of increased NO production in the lungs or aortae of cirrhotic rats, but rather suggest that decreased responsiveness of the pulmonary artery and aorta may be due to overexpression or overstimulation of endothelial eNOS. EL-NewiH et al. [34] recently compared in vitro iNOS and eNOS activities in gastric mucosal biopsies, as well as blood nitrite and nitrate levels in cirrhotic patients with portal hypertension and in normal subjects. Patients with cirrhosis and portal hypertension had both higher gastric mucosal iNOS and eNOS activities and higher blood nitrite levels than controls [34]. However, direct characterization of the NOS isoforms in vascular walls or circulating leukocytes or monocytes has not yet been performed in cirrhotic patients.

\section{Portopulmonary hypertension}

\section{Definition and incidence}

Pulmonary arterial hypertension (PH) is defined [35] as a mean pulmonary artery pressure $>25 \mathrm{mmHg}$ at rest or $>30 \mathrm{mmHg}$ during exercise, with normal pulmonary artery wedge pressure. $\mathrm{PH}$ is subclassified into primary and secondary $\mathrm{PH}$.

A moderate increase in pulmonary artery pressure $(<30$ $\mathrm{mmHg}$ ) is not unusual in patients with cirrhosis and portal hypertension [36]. This increase in pulmonary artery pressure is passive in relationship with the increases in cardiac output and/or blood volume, and is associated with a nearnormal PVR value and normal or increased pulmonary artery wedge pressure. By contrast, a severe PH with normal pulmonary artery wedge pressure and elevated PVR is more rarely observed in patients with cirrhosis and portal hypertension.

$\mathrm{PH}$ associated with cirrhosis and portal hypertension (portopulmonary hypertension), initially considered unusual, was subclassified in the 1981 National Institute of Health Registry for Characterization of Primary Pulmonary Hypertension [37] as a clinical subset of primary pulmonary hypertension (PPH). However, since then several cases of PH have been reported in patients with portal hypertension due to either cirrhosis or nonhepatic causes [37-39]. The first retrospective autopsy studies showed that the prevalence of PH ranged from $0.25-0.73 \%$ in populations with portal hypertension or cirrhosis (see references in [37]), compared with only $0.13 \%$ of those with neither abnormality. In a clinical study in 2,459 patients with biopsy-proven cirrhosis, the prevalence of clinical pulmonary hypertension was $0.61 \%$ [38]. A retrospective study in patients with surgical portosystemic shunts found a similar rate of occurrence [37]. Two prospective haemodynamic studies conducted by NaEIE et al. ([11]; and Naeije personal communication) in patients with cirrhosis and by HaDENGUE et al. [1] in patients with portal hypertension, reported in 1985 and 1991, respectively, found a prevalence of $2 \%$. This figure was considered an underestimation in the series by HADENGUE et al. [1] because all patients with known or suspected portopulmonary hypertension were excluded. Recent studies from CASTRO et al. [36] and TAMARA et al. [39] indicated a $4 \%$ and $3.5 \%$ incidence, respectively, in patients undergoing liver transplantation. Taken together, all of these studies indicate a strong association between portal hypertension and $\mathrm{PH}$, whether or not liver disease is present. Portopulmonary hypertension was therefore classified in 1993 as a form of secondary PH in the Pulmonary Hypertension Consensus Statement of the American College of Chest Physicians [40]. Simi- 
larly, human immunodeficiency virus (HIV) in-fection or appetite suppressant exposure, formerly considered to be associated with PPH, were classified as causes of secondary PH. However, the pathological features of PH associated with appetite suppressants, HIV infection or portal hypertension are indistinguishable from those observed in pure PPH [41].

Among the various conditions associated with PH, portal hypertension has a significant place. From 1981 to 1993, 436 patients with suspected PPH were referred to the Pneumology Department in Antoine Béclère Hospital. Of these $21 \%$ had used appetite suppressants, $15 \%$ were infected with HIV, 3\% had a family history of PPH, 13\% had portal hypertension and 48\% had pure PPH. In 1995, a case-control study was conducted by the International Primary Pulmonary Hypertension Study Group to assess the incidence of PPH and to investigate the roles of various suspected risk factors, especially appetite suppressant use [42]. The annual incidence of PPH was in the order of one case per 500,000 inhabitants. Use of appetite suppressants, mainly fenfluramine derivatives, was recorded in $31.6 \%$ of the 95 patients with $\mathrm{PH}$ versus $7.3 \%$ of the controls, while cirrhosis, HIV infection and a family history of PPH were found in 7.3, 3.1 and $2.1 \%$ of the patients, respectively, versus none of the controls. The bulk of available data suggests that portal hypertension is a causative factor in about $10 \%$ of the cases of $\mathrm{PH}$.

\section{Histology}

Pulmonary histological findings in patients with portopulmonary hypertension consist of the same patterns of pulmonary arteriopathy as in patients with PPH [37]. The three major patterns of pulmonary arteriopathy involving the muscular arteries are as follows: 1) isolated medial hypertrophy; 2) medial hypertrophy and concentric laminar fibroelastosis, with or without plexiform lesions, angiomatoid lesions, fibrinoid necrosis, and necrotizing arteritis; and 3) medial hypertrophy with eccentric and concentric nonlaminar fibrosis, which are believed to result from in situ microthrombosis [40]. To our knowledge, two rare histological patterns of $\mathrm{PH}$, namely pulmonary veno-occlusive disease and pulmonary capillary haemangiomatosis, have not been reported in patients with portopulmonary hypertension.

\section{Aetiology}

Three vascular abnormalities combine to cause the increase in PVR in portopulmonary hypertension: vasoconstriction, remodelling of muscular pulmonary artery walls and in situ microthrombosis.

NichoLs et al. [43] recently assigned the gene for familial PPH to chromosome 2q31-32. The lack of evidence of heterogeneity across families suggested that a single major gene may account for all familial cases of PPH. A number of candidate genes maps to the relevant genetic interval, including tissue factor pathway inhibitor (an antithrombotic agent [44]), the vitronectin receptor (a modulator of smooth muscle cell proliferation [45]), the $\alpha 1$ chain of type III collagen, the $\alpha 2$ chain of type V collagen and the homeobox D cluster. Abnormalities of these candidate genes may disrupt the regulation of vascular remo- delling, vasomotion and local coagulation. The increased risk for severe $\mathrm{PH}$ associated with various triggering factors, including appetite suppressants, HIV infection or portal hypertension, suggests that a subset of patients may have a genetic susceptibility to $\mathrm{PH}$, perhaps due to subtle mutations at the familial PPH locus.

Portal hypertension induces numerous modifications in the vascular medium, which may trigger a cascade of intracellular signals and/or cause activation or repression of various genes in the endothelial and smooth muscle cells.

Susceptible patients with portal hypertension may develop portopulmonary hypertension in response to increased vascular wall shear stress due to the increased blood flow through the lungs. Similarly, among patients with high pulmonary flow due to an ostium secundum type atrial septal defect, the incidence of $\mathrm{PH}$ varies considerably, also suggesting the involvement of host-related (genetic) factors [46].

The presence of portosystemic shunts may allow substances normally cleared by the liver to gain access to the pulmonary circulation. Increased levels of several vasoactive mediators, cytokines, or growth factors have been demonstrated in patients with portal hypertension [13]. Among these mediators, serotonin (5-hydroxytryptamine) [47, 48] and IL-1 [49] have recently been identified by our group as being of possible relevance. Serotonin causes pulmonary vasoconstriction and pulmonary artery smooth muscle proliferation [50]. It is produced in the enterochromaffin cells of the intestine and stored in the platelets. Under normal conditions, the lung vascular bed is not exposed to excessive serotonin levels, because of its position as a secondary filter located downstream from the liver and because of the ability of platelets to store large amounts of serotonin. Plasma serotonin levels are elevated in the plasma of patients with PPH, whereas platelet serotonin levels are low [47, 48]. After heart-lung transplantation, platelet serotonin storage remains impaired, suggestng that this platelet abnormality is not secondary to PPH [47]. Altered platelet serotonin storage has been reported in numerous disorders occasionally associated with secondary pulmonary hypertension [47], including liver cirrhosis [51], Raynaud's phenomenon, collagen vascular disease, use of the appetite suppressant fenfluramine, and platelet storage pool disease [48]. In addition, the fawn-hooded rat, which has a genetic defect in serotonin platelet storage, develops severe pulmonary hypertension upon exposure to modest hypoxia [52, 53]. Taken together, these findings suggest that increased plasma levels of serotonin may contribute to pulmonary hypertension in susceptible patients with portal hypertension. The IL-1 receptor blocker inhibits the development of chronic pulmonary hypertension in rats, indicating that IL-1 can promote pulmonary vascular remodelling [54]. HuMBerT et al. [49] demonstrated that serum IL-1 levels were increased in patients with PPH. Circulating IL-1 levels are also high in patients with cirrhosis [13], suggesting that this cytokine may be involved in the development of portopulmonary hypertension.

Other angiogenic factors, such as hepatocyte growth factor or vascular endothelial growth factor, may also be involved in pulmonary artery remodelling $[13,54]$. Circulating hepatocyte growth factor levels are increased in patients with liver disease [13]. Hepatocyte growth factor stimulates endothelial cell motility and mitosis, and also 
promotes angiogenesis [13]. Experimental chronic pulmonary hypertension is associated with increased expression of vascular endothelial growth factor [54]. Moreover, a case has recently been reported in which intra-arterial transfection with the gene encoding vascular endothelial growth factor resulted in the development of cutaneous spider angiomas [55] similar to those occurring in cirrhosis. Whether circulating levels of vascular endothelial growth factor are increased in chronic liver disease is not yet known.

Several factors can theoretically influence the development of PH in susceptible patients with portal hypertension. Identification of the gene responsible for familial hypertension and possibly for portopulmonary hypertension will provide important insights into the causes of these conditions.

\section{Demographics}

The demographic characteristics were different in portopulmonary hypertension and PPH in our series (from 1986 to 1996) from the Antoine Béclère Hospital ( $n=39$ and $n=140$ patients, respectively) (table 1 ). The age at diagnosis of PH was $49 \pm 13$ yrs (mean \pm SEM) in patients with portal hypertension, compared with $41 \pm 15$ yrs in patients with PPH. The patients with portopulmonary hypertension were older than those reported in the literature [37]. This difference may be ascribable to the higher prevalence of alcoholic cirrhosis as a cause of portal hypertension in our series as well as in the other French series from HADENGUE et al. [1]. The sex ratio was 1.1:1 (male to fe-male), whereas there was a 2:1 female bias in our pati- ents with $\mathrm{PPH}$, in agreement with other studies of patients with portopulmonary hypertension $[1,37]$. Given the male preponderance of alcoholic cirrhosis, this suggests that female hormones may be an independent risk factor for portopulmonary hypertension.

In our series, antinuclear antibodies were present in 19\% of patients with portopulmonary hypertension and $14 \%$ of those with PPH. Other serological markers for autoimmune disorders were also positive in a significant number of patients with portopulmonary hypertension [37].

Two patients $(5.4 \%)$ with portopulmonary hypertension in our study had Raynaud's phenomenon versus $24 \%$ in the patients with PPH. Interestingly, four patients $(11 \%)$ with portopulmonary hypertension were former users of the appetite suppressant dexfenfluramine versus $22 \%$ in the PPH group.

Table 1. - Demographic and clinical characteristics of the patients with portopulmonary hypertension and primary pulmonary hypertension seen in Antoine Béclère Hospital from 1986 to 1996

\begin{tabular}{lccc}
\hline & PH & PPH & p-value \\
\hline Number of patients & 39 & 140 & \\
Sex ratio M:F & $1.1: 1$ & $2: 1$ & $<0.05$ \\
Antinuclear antibodies \% & 19 & 14 & Ns \\
Raynaud's phenomenon \% & 5 & 24 & $<0.01$ \\
NYHA \% & 57 & 25 & \\
$\quad$ Grade I and II & 43 & 75 & $<0.001$ \\
Grade II and IV & & \\
\hline
\end{tabular}

PH: portopulmonary hypertension; PPH: primary pulmonary hypertension; M: male; F: female; NYHA: New York Heart Association grades of dyspnoea; ss: nonsignificant.
Relationship between liver disease, portal hypertension and portopulmonary hypertension

A nonhepatic cause of portal hypertension was present in $10 \%$ of the patients, including one patient with BuddChiari syndrome. All remaining patients had both chronic liver disease and portal hypertension. This is consistent with other series and case reports [37] indicating that portal hypertension rather than liver disease is the key factor for the development of portopulmonary hypertension. Similarly, the severity of liver failure, as estimated by the Child-Pugh's score, was not correlated with PVR in the prospective study by HADENGUE et al. [1]. In most series, the diagnosis of portal hypertension antedated that of portopulmonary hypertension in the majority of the patients.

Clinical presentation, haemodynamics, response to vasodilators and survival in patients with portopulmonary hypertension associated with portal hypertension

In the prospective study by $\mathrm{H}_{\mathrm{ADENGUE}}$ et al. [1], $60 \%$ of patients with portopulmonary hypertension were asymptomatic and PVR values were lower in asymptomatic than in symptomatic patients. In our series, exertional dyspnoea was consistently present. However, the New York Heart Association (NYHA) grades of dyspnoea were lower in the patients with portal hypertension than in those with PPH (grades I and II, 57 versus 25\%; grades III and IV, 43 versus $75 \%$; $\mathrm{p}<0.05$ ). There were no significant differences in the frequency of chest pain (15 versus $22 \%$ ), syncope ( 29 versus $22 \%$ ), or haemoptysis (4 versus $11 \%$ ). Spirometric results, blood gas values, chest radiographs and perfusion lung scans were also similar in the two groups.

Mean pulmonary pressure was lower in the patients with portopulmonary hypertension than in the patients with $\mathrm{PPH}(56 \pm 13$ versus $63 \pm 15 \mathrm{mmHg}$, respectively, $\mathrm{p}=0.02)$, whereas cardiac index and mixed venous oxygen saturation were higher $\left(2.7 \pm 1.1\right.$ versus $2.2 \pm 0.6 \mathrm{~L} \cdot \mathrm{min}^{-1} \cdot \mathrm{m}^{-2}, \mathrm{p}=$ 0.0004 , and $65 \pm 11$ versus $57 \pm 11 \%, \mathrm{p}=0.0003$ ), yielding lower calculated PVR values (table 2 ). The other haemodynamic values were similar in the two groups. These

Table 2. - Haemodynamics of the patients with portopulmonary hypertension $(\mathrm{PH})$ and primary pulmonary hypertension $(\mathrm{PPH})$ see in Antoine Béclère Hospital from 1986 to 1996

\begin{tabular}{|c|c|c|c|}
\hline & $\mathrm{PH}$ & PPH & p-value \\
\hline Number of patients & 39 & 140 & \\
\hline $\begin{array}{l}\text { Mean pulmonary artery } \\
\text { pressure } \mathrm{mmHg}\end{array}$ & $56 \pm 13$ & $63 \pm 15$ & 0.02 \\
\hline Right atrial pressure $\mathrm{mmHg}$ & $10 \pm 6$ & $9.5 \pm 5$ & NS \\
\hline $\begin{array}{l}\text { Pulmonary wedge } \\
\text { pressure } \mathrm{mmHg}\end{array}$ & $9 \pm 9$ & $8 \pm 11$ & NS \\
\hline $\begin{array}{l}\text { Mean systemic arterial } \\
\text { pressure } \mathrm{mmHg}\end{array}$ & $97 \pm 15$ & $93 \pm 15$ & NS \\
\hline Cardiac index $\mathrm{L} \cdot \mathrm{min} \cdot \mathrm{m}^{-2}$ & $2.7 \pm 1.1$ & $2.2 \pm 0.6$ & 0.0004 \\
\hline $\begin{array}{l}\text { Pulmonary vascular resistance } \\
\mathrm{mmHg} \cdot \mathrm{L} \cdot \mathrm{min} \cdot \mathrm{m}^{-2}\end{array}$ & $21 \pm 9$ & $29 \pm 12$ & 0.0003 \\
\hline Mixed venous saturation $\%$ & $65 \pm 11$ & $57 \pm 11$ & 0.0003 \\
\hline $\begin{array}{l}\text { \% decrease from baseline PVR } \\
\text { with prostacyclin }\end{array}$ & $20 \pm 17$ & $25 \pm 19$ & ns \\
\hline
\end{tabular}

Values are shown as mean \pm SEM. PVR: pulmonary vascular re-sistance; Ns: nonsignificant. 
findings are comparable to those reported in the National Institute of Health Registry for Characterization of Primary Pulmonary Hypertension [56].

The results of pharmacological vasodilation testing using intravenous prostacyclin were similar in the two groups, with mean PVR decreases from baseline of $20 \pm 17 \%$ versus $25 \pm 19 \%$ (nonsignificant) in the patients with portopulmonary hypertension and $\mathrm{PPH}$, respectively. The proportions of patients having a reduction of PVR of at least $20 \%$ were similar in the two groups (43 versus $57 \%$ ), and $37 \%$ of patients in the portopulmonary hypertension group versus $36 \%$ in the PPH group were subsequently treated with various oral vasodilators. Following KNEussL et al. [57], pati-ents were classified as responders (reduction of PVR S20\% and reduction of mean pulmonary artery pressure Š20\%) or nonresponders to prostacyclin. Using this criterion, $16 \%$ of patients were classified as responders in the PPH group and none in the portopulmonary hypertension group.

Although insufficient results are available in the literature to allow reliable comparisons with PPH, patients with portopulmonary hypertension are generally believed to have a substantially shorter survival rate [37]. However, the patients with portopulmonary hypertension survived longer (fig. 3) than those with PPH (median survival time, 57 months versus 31 months; $\mathrm{p}<0.05$ ). Actuarial survivals at 1,2 and $5 \mathrm{yrs}$ in the portopulmonary hypertension and PPH groups were 76 versus $64 \%, 72$ versus $54 \%$, and 50 versus $25 \%$, respectively $(\mathrm{p}<0.05)$. Multiple regression analysis of the haemodynamic variables as predictors of survival (Cox model) showed that the cardiac index was the most significant prognostic variable in both groups $(\mathrm{p}<0.01)$. The cardiac index was lower in the PPH group, a finding that may explain why death was more frequently related to haemodynamic complications in the PPH group than in the portal hypertension group ( 80 versus $52 \%, \mathrm{p}<$ $0.05)$.

\section{Treatment}

Oral vasodilator therapy has been shown to improve survival in the subset of $\mathrm{PPH}$ patients with a positive vasodilator challenge [58]. In our study, $37 \%$ of patients

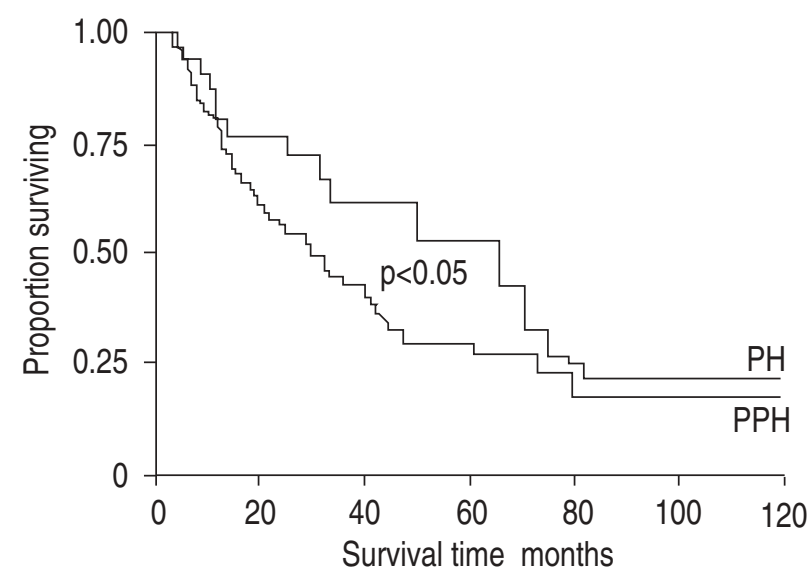

Fig. 3. - Actuarial survival curves in the series from Antoine Béclère Hospital. The graph compares patients with portal hypertension-associated pulmonary hypertension $(\mathrm{PH}, \mathrm{n}=39)$ with patients with primary pulmonary hypertension $(\mathrm{PPH}, \mathrm{n}=140) . \mathrm{p}<0.05$, significant difference between groups. with portopulmonary hypertension and $36 \%$ with PPH were treated with oral vasodilators. We do not recommend anticoagulation in portopulmonary hypertension because of the risk of bleeding. Therapy with $\beta$-blocking agents is not advisable because it can further decrease cardiac output. Long-term prostacyclin therapy given by continuous intravenous infusion has been reported to improve exercise tolerance, quality of life and survival in patients with PPH independently of the presence of a positive response to acute vasodilator challenge [58]. Three patients with severe portopulmonary hypertension are under prostacyclin therapy, which has been associated with substantial improvements in their haemodynamic characteristics and exercise tolerance. A recent report indicates that continuous infusion of epoprostenol is an effective chronic therapy for patients with portopulmonary hypertension [59].

There have been reports of the improvement, persistence or development of $\mathrm{PH}$ following liver transplantation [37]. In the retrospective study from TAMARA et al. [39], among 226 patients undergoing liver transplantation eight had moderate portopulmonary hypertension (pulmonary arterial pressure: $33.4 \pm 2.3 \mathrm{mmHg}$, range $28-38 \mathrm{mmHg}$ ). Postoperative complications were similar in the patients with and without portopulmonary hypertension, and postoperative mortality was one patient in each group. In a recent study by CASTRO et al. [36] the patients with or without mode-rate portopulmonary hypertension had similar short-term but also long-term survival after liver transplantation. At present, liver transplantation should not be considered in patients with severe portopulmonary hypertension. Indeed, most investigators agree that preserved right ventricular function is an absolute requirement for liver transplantation. Combined heart-lung-liver or lung-liver transplantation can remain the only therapeutic option in these patients. Further studies of outcomes are needed to determine the role of liver transplantation in patients with moderate portopulmonary hypertension.

\section{Hepatopulmonary syndrome}

\section{Definition}

Hepatopulmonary syndrome (HPS) is a triad of advanced liver disease, intrapulmonary vascular dilatations and increased alveolar-arterial oxygen gradient $(>20 \mathrm{mmHg})$ while breathing room air [60]. Recent studies in patients with end-stage liver disease found an incidence of intrapulmonary vascular dilatations of $13-47 \%$ using contrast echocardiogram, which was associated with hypoxaemia in about half of the cases [60].

\section{Pathological changes in HPS}

Pulmonary vascular abnormalities are thought to be the main cause of severe hypoxaemia in HPS, and are the distinctive feature of HPS. They were first described by BERTHELOT et al. [61] in autopsy specimens from pati- ents with HPS. According to KRowKA and co-workers [60, 62], they occur either as vascular dilatations at the capillary and precapillary levels, ranging from $15-500 \mu \mathrm{m}$ in diameter and located close to the gas exchange units, or as 
larger arteriovenous communications. Because these vascular abnormalities predominate in the middle to lower lung fields where gravitational effects result in increased blood flow, worsening of hypoxaemia can occur in the upright position. Precapillary arteriovenous communications (that can resemble spider naevi) are less common than vascular dilatations. BERTHELOT et al. [61] found capillary enlargement in all 14 patients studied, whereas arteriovenous communication was present in only one patient. Other vascular abnormalities include pleural spider naevi and portal vein-to-pulmonary vein anastomoses, which are not believed to contribute greatly to hypoxaemia in HPS [60, 63].

\section{Mechanism of hypoxaemia}

Mild hypoxaemia is found in the apparent absence of cardiac and pulmonary disease in approximately onethird of patients with cirrhosis [63]. Recent studies using an inert gas elimination technique have provided new insights into the causes of this hypoxaemia. Mild arterial hypoxaemia is due to ventilation/perfusion mismatching characterized by an increase in perfusion while ventilation is preserved. Impaired hypoxic vasoconstriction and increased pulmonary blood flow may contribute to these ventilation/perfusion abnormalities [7, 9, 10]. In the most severe cases, major intrapulmonary shunting and diffusion limitation may coexist $[63,64]$ as a result of the intrapulmonary vascular dilatations. Because supplemental oxygen enhances oxygenation more than would be expected with true anatomic shunts, a mechanism called "diffusionperfusion impairment" $[60,64]$ has been postulated, in which the increase in capillary diameter prevents oxygen molecules from diffusing to the centre of the capillary to oxygenate the haemoglobin. Supplemental oxygen provides enough driving pressure to overcome partially this relative diffusion defect. This diffusion impairment is made worse by the high cardiac output, which reduces the capillary transit time and therefore the amount of time available for oxygen diffusion to occur. Other mechanisms, such as decrease in the affinity of haemoglobin for oxygen and portopulmonary shunt, have been essentially dismissed as causes of severe hypoxaemia in HPS [63]. However, CRAWFoRd et al. [65] and WaGNER [66] have recently highlighted the complexity of hypoxaemia caused by cirrhosis and suggested that we still do not have the tools to understand fully its mechanism.

\section{Pulmonary haemodynamics and mechanisms of pulmo- nary intravascular dilatations}

The causes of HPS are unknown but are generally believed to involve an imbalance between vasoconstrictors and vasodilators (such as NO), and/or between hepatic factors inhibiting and stimulating vascular cell growth (such as hepatic growth factor or vascular endothelial growth factor).

The HPS is characterized by reduced PVR, normal or low pulmonary arterial pressure and high cardiac output. In a prospective study from VACHERY et al. [67], 14\% of 120 patients with cirrhosis had an arterial oxygen tension $\left(\mathrm{Pa}, \mathrm{O}_{2}\right)$ of $<9.3 \mathrm{kPa}(70 \mathrm{mmHg})$. PVR was lower in these hypoxaemic patients $\left(\mathrm{Pa}_{\mathrm{a}} \mathrm{O}_{2}<70 \mathrm{mmHg}\right)$, whereas systemic haemodynamics and cardiac index were simi- lar in hypoxaemic and nonhypoxaemic patients, suggesting accentuation of the pulmonary vasodilatation in the cirrhotic patients with HPS. RODRIGUEz-RoIsin et al. [7] suggested that, as liver failure progresses, patients with cirrhosis may exhibit a gradual decrease in pulmonary vascular tone associated with development of intrapulmonary vascular dilatations, and ultimately with complete loss of pulmonary vasoreactivity. Increased NO production has been suggested as a contributor to the gas exchange abnormality in HPS. CREMONA et al. [18] found increased concentrations of exhaled NO in three patients with HPS. One HPS patient received an orthotopic liver transplant and achieved normoxaemia after 3 months, at the same time as exhaled NO levels returned to normal [18]. In the study by Rolla et al. [20] on 45 patients with cirrhosis, the nine patients with HPS had higher exhaled NO concentrations than patients without HPS. In all of these patients, there was a significant correlation between exhaled NO and the alveolar-arterial oxygen gradient. In an anecdotal case of HPS, guanylate cyclase inhibition by methylene blue resulted in increased systemic arterial pressure and improvements in pulmonary shunting and hypoxaemia [68]. All of these studies suggest that NO produced in the lung may play an important role in determining oxygenation abnormalities and pulmonary haemodynamics in HPS.

Chang and Ohara [27] reported that rats with bile duct ligation-induced cirrhosis exhibited features of HPS, including high cardiac output with low systemic and pulmonary vascular resistances, an increased alveolar-arterial oxygen gradient and a loss of hypoxic vasoconstriction. In the same model, FALLoN et al. [69] demonstrated intrapulmonary vascular dilatations by injecting microspheres $5.5-10 \mu \mathrm{m}$ in diameter intravenously and measuring the size and number of microspheres bypassing the lungs in arterial blood. A recent study from the same authors [31] indicated that pulmonary endothelial NOS levels increased after bile duct ligation in rat and correlated with alterations in gas exchange. Moreover, intralobar pulmonary artery rings from these animals showed enhanced basal NO activity and an NO-mediated impairment in vasoactive response to phenylephrine. Interestingly, rats with a similar degree of portal hypertension induced by partial ligation of the portal vein had also a hyperdynamic circulation but no alteration in gas exchange and no detectable alteration in the pulmonary vasculature [31]. This observation supports the theory that the development of portal hypertension and a hyperdynamic circulation alone is not sufficient to cause pulmonary vascular alterations in rats. Preliminary study from Luo et al. [70] found an enhanced hepatic production and increased plasma levels of endothelin-1 after bile duct ligation in rats, which correlated directly with alterations in gas exchange and lung eNOS levels. This suggests that endothelin-1 produced in the liver during hepatic injury may serve as an endocrine mediator of intrapulmonary vasodilatation in HPS.

SChraufnagel et al. [71] recently measured pulmonary capillary size, density, and branching frequency in the rat after chronic bile duct ligation. All three parameters were increased, suggesting that the pathogenesis of HPS may 
result from both vascular dilatation and increased angiogenesis. The presence of cutaneous and pleural spider naevi in patients with HPS lends support to this possibility $[61,64]$.

It has been hypothesized that the pulmonary vascular bed needs something to maintain vascular tone and to control angiogenesis, which exits the liver via the hepa- tic veins. Recent observations in patients with congenital heart disease associated with diversion of the hepatic venous blood from the lung support this hypothesis. Numerous studies in patients with congenital heart disease reported development of diffuse pulmonary arteriovenous malformations and vascular dilatations (angiographically and histologically similar to those found in HPS) after anastomosis of the superior vena cava to the right pulmonary artery [72]. No such vascular abnormalities have been reported after total cavopulmonary anastomosis, which directs the entire systemic venous return (including hepatic venous blood) to the pulmonary arterial bed. Moreover, recent studies indicate that redirection of hepatic venous flow to the pulmonary bed, either by surgical inclusion of hepatic vein [73] or by heart transplantation, can reverse these vascular abnormalities [74, 75]. These findings suggest that a hepatic factor contained in normal hepatic venous blood plays a role in the control of pulmonary angiogenesis. HPS has been reported in patients with hepatic and nonhepatic portal hypertension, thus suggesting that the absence of a hepatic agent in the pulmonary vasculature, by virtue of either poor hepatic synthetic function or poor hepatic venous blood flow, could result in exaggerated angiogenesis in HPS.

\section{Clinical manifestations}

Symptoms related to liver disease and/or portal hypertension are found in $82 \%$ of patients with HPS, whereas dyspnoea is present in only $18 \%[60,76]$. Platypnoea, defined as dyspnoea induced by the upright position, is a characteristic but uncommon feature of HPS. Finger clubbing is common, and the presence of spider naevi has been suggested as one of the most sensitive clinical markers $[60,76]$. The association of portal hypertension, cutaneous spider naevi, clubbing and hypoxaemia is strongly suggestive of HPS [60,76]. Paradoxical embolisms or cerebral abscesses, such as observed in hereditary haemorrhagic telangiectasia with pulmonary arteriovenous malformations, have not been reported in HPS.

Impaired oxygenation varies from a mild increase in the alveolar-arterial oxygen difference $(\breve{S} 15 \mathrm{mmHg}$ ) to severe arterial hypoxaemia $(<60 \mathrm{mmHg})[60,76]$. Severe hypoxaemia is uncommon in the absence of independent lung disease, and strongly suggests HPS. In the largest available retrospective study of patients with HPS, KROWKA and CORTESe [77] found that $59 \%$ had a $\mathrm{Pa}, \mathrm{O}_{2}<8.0 \mathrm{kPa}(60$ $\mathrm{mmHg}$ ). Orthodeoxia, defined as arterial deoxygenation accentuated in the upright position (a decrease $>0.4 \mathrm{kPa}$ $(3 \mathrm{mmHg})$ ) versus the supine $\mathrm{Pa}, \mathrm{O}_{2}$, has been reported in $5 \%$ of all patients with cirrhosis and in $>80 \%$ of patients with HPS. In the series by KRowKA and CORTESE [77], the mean fall in $\mathrm{Pa}, \mathrm{O}_{2}$ was $1.6 \mathrm{kPa}(12 \mathrm{mmHg})$ when patients stood from the supine position. Most patients with HPS respond poorly to $100 \%$ inspired oxygen $\left(\mathrm{Pa}, \mathrm{O}_{2}<39.9 \mathrm{kPa}\right.$ $(300 \mathrm{mmHg}))$ because of the shunting through the intra- pulmonary vascular dilatations. However, room air $\mathrm{Pa}_{\mathrm{a}} \mathrm{O}_{2}$ values fail to predict the response to pure oxygen. Alveolar hyperventilation with hypocapnia is common. Diffusing capacity is low in $83 \%$ of patients with HPS, whereas spirometric abnormalities are unusual.

In most studies, hypoxaemia was not consistently correlated with the severity of the liver disease. However, these studies were retrospective or included only small numbers of patients with no control group of nonhypoxaemic cirrhotic patients. In a prospective study by VACHÉRY et al. [67], $14 \%$ of 120 cirrhotic patients had a $\mathrm{Pa}, \mathrm{O}_{2}$ of $<9.3$ $\mathrm{kPa}(70 \mathrm{mmHg})$, and this hypoxaemic subset was characterized by more severe liver failure with a higher ChildPugh's score and a higher proportion of grade $\mathrm{C}$ disease, as well as by a higher hepatic venous pressure gradient. These findings suggest that the severity of HPS may parallel the severity of liver failure, although the gas ex-change abnormalities occasionally antedate the development of liver dysfunction, and oxygenation sometimes decreases gradually despite stable liver function. Overall mortality in the study by KRowKA and CORTESE [77] was $41 \%$, and the deaths were due to nonpulmonary causes such as gastrointestinal bleeding.

\section{Diagnosis}

Contrast-enhanced echocardiography (fig. 4) has become the gold standard for demonstrating the presence of intrapulmonary vascular dilatations $[60,76,77]$. This method uses agitated saline or indocyanine green, which produces microbubbles at least $15 \mu \mathrm{m}$ in diameter. When injected peripherally, the microbubbles are trapped in the pulmonary capillaries and absorbed. Intracardiac and intrapulmonary shunting can be differentiated based on the timing of bubble appearance in the left atrium. In intracardiac right-to-left shunts, the bubbles appear in the left heart chambers within three heartbeats after their appearance in the right heart chambers, whereas the interval is four to six heartbeats in intrapulmonary shunts. Contrast-enhanced echocardiography neither quantifies the shunting nor differentiates between intrapulmonary vascular dilatations and direct arteriovenous anastomoses. However, by detecting the contrast within specific pulmonary veins, transoesophageal echocardiography allows the determination of the main sites of intrapulmonary vascular dilatations or arteriovenous communications. A recent study by VEDRINNE et al. [78] demonstrated the higher sensitivity of transoesophageal echocardiography with the use of gelatin contrast solution in detecting intrapulmonary shunting. The proportion of chronic liver disease patients with a positive contrast-enhanced echocardiogram has ranged from 13-47\% [60]. Approximately half of the patients with a positive contrast echocardiogram also exhibited hypoxaemia and were classified as having HPS. The remaining patients may have had a "forme fruste" of HPS [60, 76].

A second method of detecting HPS is the technetium99 albumin macroaggregate body scan (fig. 5). Because albumin macroaggregates exceed $20 \mu \mathrm{m}$ in diameter, they are normally trapped in the pulmonary vasculature. In patients with intracardiac or intrapulmonary shunts, however, some of the radiolabelled albumin escapes from the pulmonary vascular bed and is taken up by the brain, kidneys 

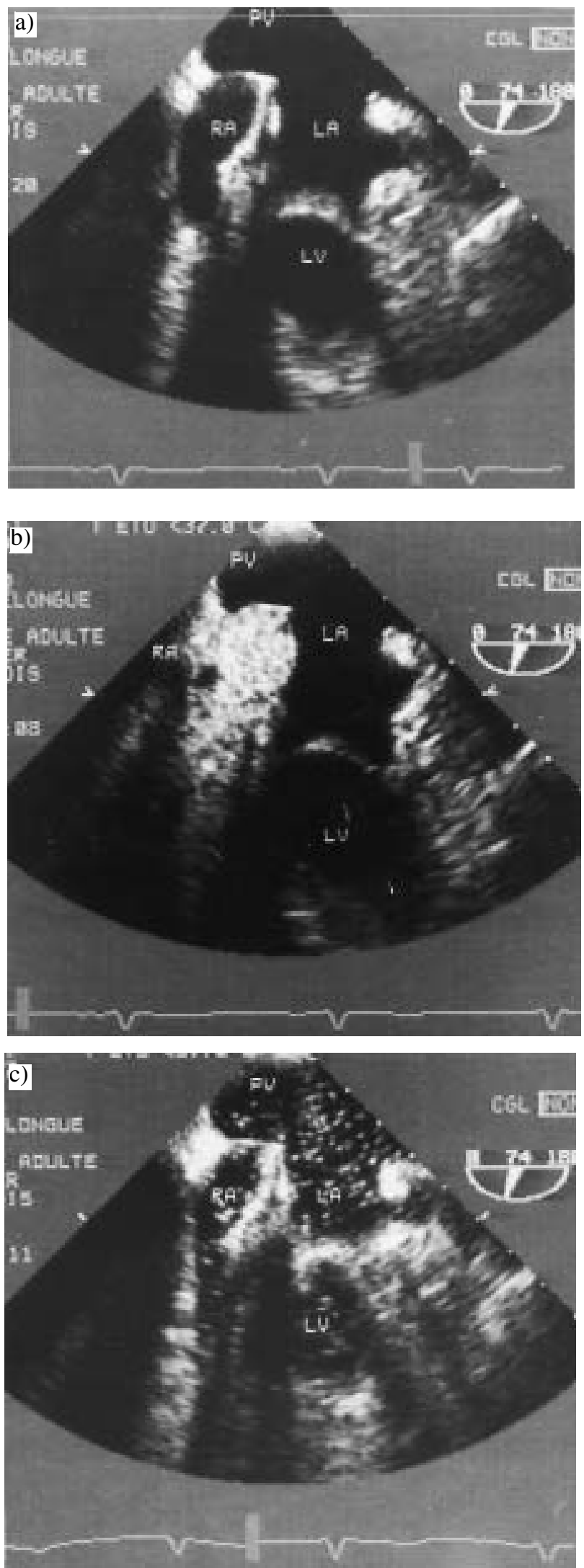

Fig. 4. - Contrast-enhanced transoesophageal multiplan echocardiograms in a patient with hepatopulmonary syndrome showing: a) normal right atrium (RA), pulmonary vein (PV), left atrium (LA) and left ventricle (LV); b) opacification of RA with microbubbles; and c) opacifications of PV, LA and LV, suggesting intrapulmonary vascular dilatations.

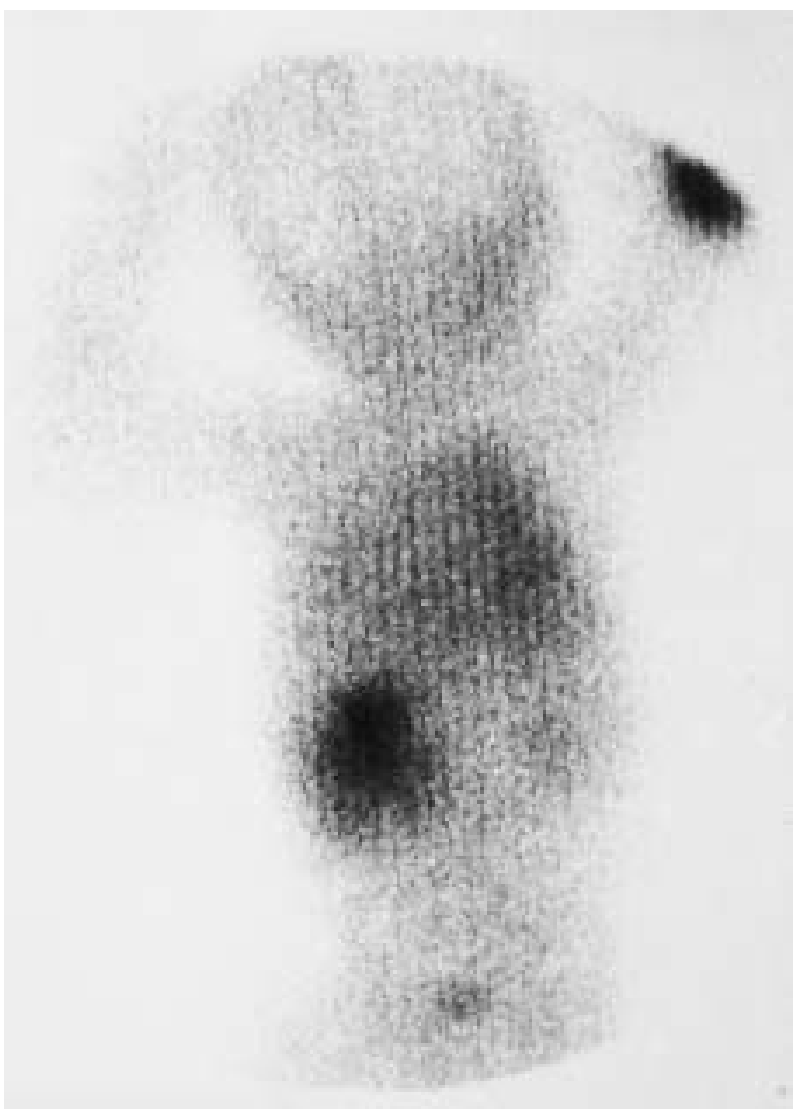

Fig. 5. - Technetium-99 macroaggregated albumin perfusion body scan in a child with hepatopulmonary syndrome showing extrapulmonary radionuclide uptake in the brain, liver and kidneys. In patients with intrapulmonary shunts, some of the radiolabelled albumin escapes from the pulmonary vascular bed and is taken up by the brain, kidneys and liver.

and liver. The magnitude of the shunt can be estimated by calculating the ratio of systemic to total body radioactivity. Estimations obtained using this method exceed by far the functional estimates provided by the oxygen method $[64,66,76]$. This may be because dilated intrapulmonary vessels may continue to participate in gas exchange, especially when the driving pressure is increased by the administration of pure oxygen. The disadvantages of technetium-99 macroaggregate albumin scanning include the inability to distinguish intracardiac from intrapulmonary shunting.

Lung perfusion scanning and contrast echocardiography for the diagnosis of HPS have recently been compared by AвRAMs et al. [79] in 40 outpatients with cirrhosis. Fifteen patients $(38 \%)$ had a positive contrast echocardiogram, and seven of these $15(17.5 \%)$ were classified as having HPS. The lung scan was positive in only three patients $(7.5 \%)$, all of whom fulfilled criteria for HPS and had a positive contrast echocardiogram.

A pulmonary arteriography study in seven patients with HPS [77] found two angiographic patterns, the type I or diffuse pattern and the type II or focal pattern. The "minimal" type I pattern is characterized by normal vessels or finely diffuse spidery vascular abnormalities during the arterial phase. The "advanced" type I pattern is seen as a diffuse spongy or blotchy appearance. The type II pattern, 
which is infrequent, consists of focal arteriovenous malformations similar to those seen in hereditary haemorrhagic telangiectasia. Patients with advanced type I and type II patterns may demonstrate a poor response to $100 \%$ oxygen. Patients with a type II pattern should be considered for embolization [60], because type II lesions have never been found to regress and may carry a risk of cerebral emboli and abscess.

The following algorithm has been proposed for the evaluation of HPS [79, 80]. Contrast echocardiography should be used as the screening test in patients with a $P \mathrm{a}, \mathrm{O}_{2}<9.3 \mathrm{kPa}(70 \mathrm{mmHg})$ while breathing room air. A negative result rules out the diagnosis of HPS, whereas a positive result in a hypoxaemic patient without intrinsic bronchopulmonary disease strongly suggests HPS. In a hypoxaemic patient with intrinsic bronchopulmonary disease and a positive contrast echocardiogram, a positive lung scan indicates that HPS is contributing to the hypoxaemia. In addition, patients with a poor response to $100 \%$ oxygen $\left(P \mathrm{a}, \mathrm{O}_{2}<20 \mathrm{kPa}(150 \mathrm{mmHg})\right)$ should be evaluated by pulmonary angiography.

\section{Treatment}

Several treatments have been used in HPS to no clear advantage, including almitrine bismesylate, indomethacin, tamoxifen, somatostatin analogue, sympathomimetics, $\beta$ blockers, methylene blue and plasma exchange [60].

$\mathrm{Pa}, \mathrm{O}_{2}$ measurement while breathing room air and $100 \%$ oxygen is useful for determining which patients require supplemental oxygen.

Pulmonary angiography has been recommended in patients with a $\mathrm{Pa}, \mathrm{O}_{2}$ of $<20 \mathrm{kPa}(150 \mathrm{mmHg})$ while breathing $100 \%$ oxygen, since this has been shown to indicate a possibility of arteriovenous communications amenable to embolization therapy [81].

CADRANel et al. [82] reported a case suggesting that HPS may be reversible if the underlying liver disease can be corrected. The patient had HPS and liver failure due to angioimmunoblastic lymphadenopathy, and experienced a dramatic decrease in pulmonary shunting after treatment with cyclophosphamide and corticosteroids.

Also, reversal of HPS has recently been reported after liver transplantation, and consequently HPS with severe hypoxaemia is no longer considered a contra-indication to liver transplantation. This finding is consistent with the observations that redirection of hepatic venous flow to the pulmonary bed can reverse the pulmonary arteriovenous abnormalities in some patients with congenital heart disease [72-75]. The recent prospective study from BatTAGLIA et al. [83] indicated that 19 of the 22 patients with increased shunting improved following liver transplantation. In a recent report, KRowKA et al. [80] reviewed the 81 reported cases of liver transplantation in patients with HPS. Improvement or normalization of hypoxaemia occurred in $82 \%$ of transplant recipients within 15 months after transplantation. In one patient with persistent HPS, direct arteriovenous communications were still present after liver transplantation, and the $\mathrm{Pa}, \mathrm{O}_{2}$ returned to normal following their embolization. Sixteen percent of the patients died within 3 months after liver transplantation. A $P \mathrm{a}, \mathrm{O}_{2}$ of $\partial 6.7 \mathrm{kPa}(50 \mathrm{mmHg})$ while breathing room air was associated with a higher mortality rate. Transplantation success rates were highest and morbidity rates lowest when $\mathrm{Pa}_{\mathrm{a}} \mathrm{O}_{2}$ values while breathing $100 \%$ oxygen were S553.2 $\mathrm{kPa}(400 \mathrm{mmHg})$ in the supine position. The following recommendations have been proposed by KROWKA et al. [80]: in patients who have a good response to $100 \%$ oxygen, liver transplantation can be expected to be followed by resolution of the HPS, whereas in patients with severe hypoxaemia and a poor response to $100 \%$ oxygen the decision to perform liver transplantation should be made on a case-by-case basis according to the results of the pulmonary angiogram. There are no data supporting lung transplantation or combined lung-liver transplantation for the treatment of HPS.

HPS and portopulmonary hypertension: distinctions, similarities and association

VACHIÉRY et al. [67] recently studied the relationships between hypoxaemia and pulmonary haemodynamics in 120 consecutive patients with cirrhosis and normal pulmonary function. The patients with hypoxaemia did not have portopulmonary hypertension, and vice versa, suggesting that HPS and portopulmonary hypertension were unrelated complications of cirrhosis. Table 3 summarizes the differences and similarities [84] between HPS and portopulmonary hypertension (fig. 6).

Severe hypoxaemia and portopulmonary hypertension has been reported, however, in a few patients with liver disease. RAFF et al. [85] recently reported two patients with cirrhosis under long-term $\beta$-blocker therapy who presented with refractory hypoxaemia and signs of portopulmonary hypertension. However, contrast echocardiography demonstrated a right-to-left intracardiac shunt through a patent foremen ovale with no intrapulmonary shunt. The portopulmonary hypertension and intracardiac shunt eventually disappeared after discontinuation of $\beta$ blocker therapy. Two patients reported by KROWKA and CORTESE [77] had portopulmonary hypertension and contrast echocardiographic evidence of intrapulmonary vascular shunting. DAwSON et al. [86] reported two cases of portopulmonary hypertension in patients with type 1 Gaucher disease who had hepatomegaly, severe hypoxaemia and intrapulmonary vascular dilatations demonstra-ted by contrast echocardiography. In one patient reported by TASAKA et al. [87], HPS occurred as a complication of portopulmonary hypertension, manifesting as a gradual worsening of the hypoxaemia with extrapulmonary radionuclide uptake, and autopsy findings included hypertensive pulmonary arteriopathy and pulmonary precapillary dilatations. In contrast, a case in which portopulmonary hypertension occurred in a cirrhotic patient with pre-existing HPS has also been reported (Fournier M, personal communication); in this patient, the development of portopulmonary hypertension was associated with gradual improvements in the hypoxaemia and extrapulmonary ra-dionuclide uptake. All of these observations suggest that HPS and portopulmonary hypertension are not mutually exclusive complications of portal hypertension. Vascular hyperplasia, which commonly manifests in cirrhosis as spider naevi and portocaval anastomosis, is also present in pulmonary precapillary and 
Table 3. - Similarities and differences between hepatopulmonary syndrome and portopulmonary hypertension

\begin{tabular}{|c|c|c|}
\hline & Hepatopulmonary syndrome & Portopulmonary hypertension \\
\hline Causes & $\begin{array}{l}\text { Hepatic or nonhepatic } \\
\text { portal hypertension }\end{array}$ & $\begin{array}{l}\text { Hepatic or nonhepatic } \\
\text { portal hypertension }\end{array}$ \\
\hline Lung pathology & $\begin{array}{l}\text { Precapillary and capillary vascular } \\
\text { dilatations }\end{array}$ & $\begin{array}{l}\text { Obstructive } \\
\text { arteriopathy }\end{array}$ \\
\hline Incidence $\%$ & $20-50$ & $2-5$ \\
\hline Clinical manifestations & $\begin{array}{l}\text { Progressive dyspnoea } \\
\text { Frequent cyanosis } \\
\text { Frequent digital clubbing } \\
\text { Frequent spider naevi }\end{array}$ & $\begin{array}{l}\text { Progressive dyspnoea } \\
\text { Rare cyanosis }\end{array}$ \\
\hline$P_{\mathrm{a}, \mathrm{O}_{2}}$ & $\begin{array}{c}\text { Hypoxaemia frequently severe } \\
\left(\mathrm{Pa}, \mathrm{O}_{2}<6.7 \mathrm{kPa}(50 \mathrm{mmHg})\right) \\
\text { Orthodeoxia common }\end{array}$ & $\begin{array}{l}\text { Hypoxaemia usually } \\
\text { minimal }\end{array}$ \\
\hline Chest radiograph & Usually normal & $\begin{array}{c}\text { Cardiomegaly } \\
\text { Hilar enlargement }\end{array}$ \\
\hline Contrast echocardiography & $\begin{array}{l}\text { Delayed positive microbubble } \\
\text { opacification of the left atrium } \\
\text { (constant) }\end{array}$ & $\begin{array}{l}\text { Immediate positive microbubble } \\
\text { opacification of the left atrium } \\
\text { in case of patent foramen ovale } \\
\text { (uncommon) }\end{array}$ \\
\hline Pulmonary vascular resistance & Normal or low & $\begin{array}{c}\text { Dilated right ventricle } \\
\text { Elevated }\end{array}$ \\
\hline $\begin{array}{l}\text { Relationship with severity } \\
\text { of liver disease }\end{array}$ & Yes & No \\
\hline $\begin{array}{l}\text { Resolution with liver } \\
\text { transplantation }\end{array}$ & Yes & Uncertain \\
\hline
\end{tabular}

${\mathrm{Pa}, \mathrm{O}_{2}}_{2}$ oxygen tension in arterial blood.

\section{Spectrum of pulmonary vascular complications in portal hypertension}

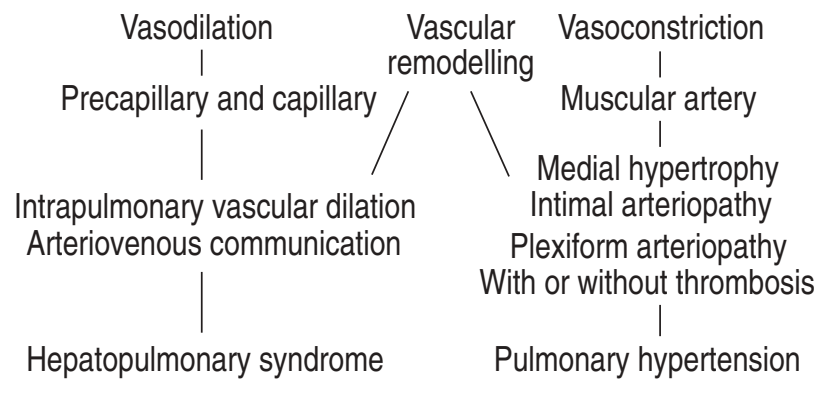

Fig. 6. - Schema of the spectrum of vascular disorders in portal hypertenstion.

capillary vessels in HPS and in muscular arteries in portopulmonary hypertension, consistent with a role for vascular growth factors. The difference in these sites of microvascular changes may account for the coexistence of HPS and portopulmonary hypertension in some patients.

\section{Conclusions}

Recent experimental and clinical studies indicate that the liver exerts a critical influence on the regulation of pulmonary vascular tone and angiogenesis. The pathophysiology of portopulmonary hypertension and hepatopulmonary syndrome may involve an imbalance between vasoconstrictors and vasodilators, and/or between factors inhibiting and stimulating vascular cell proliferation. Hepatopulmonary syndrome and portopulmonary hypertension are apparently at opposite ends of the wide spectrum of pulmonary circulatory abnormalities observed in chronic liver disease (fig. 6). Whereas pulmonary vasodilation is usual in liver disease and may represent a forme fruste of hepatopulmonary syndrome, the prevalence of portopulmonary hypertension is much lower and suggests a genetic predisposition. The severity of hepatopulmonary syndrome seems to parallel the severity of liver failure, whereas no simple relationship has been identified between hepatic impairment and the severity of portopulmonary hypertension. Resolution of hepatopulmonary syndrome is common after liver transplantation, which has an uncertain effect in portopulmonary hypertension.

\section{Perspective}

Many questions about the pathophysiology, diagnosis and treatment of HPS and portopulmonary hypertension remain unanswered.

1) What are the mediators that might alter pulmonary NOS expression in cirrhosis?

2) Does NO inhibition in the pulmonary vasculature improve intrapulmonary vascular dilatation and gas exchange?

3) What are the angiogenic factors implicated in the development of cutaneous spider naevi, HPS and portopulmonary hypertension?

4) Is there a genetic predisposition in portopulmonary hypertension?

5) What is the clinical significance of evidence on contrast echocardiography of intrapulmonary vascular dilatation without hypoxaemia?

6) Could the detection of increased levels of exhaled NO become a sensitive marker of HPS?

7) What are the characteristics that predict survival and the resolution of HPS and portopulmonary hypertension after liver transplantation?

The formation of a national database by M. Krowka and S. Mandell on portopulmonary hypertension and hepatopulmonary syndrome will help to elucidate further some of these challenging issues [88]. 
Acknowledgements: The authors wish to thank F. Lacourt Gayet, A.T. Dinh-Xuan and J. Losay for their stimulating comments, and M. Wartsky and J.C. Dib for providing the perfusion scan and the contrast echocardiogram, respectively.

\section{References}

1. Hadengue A, Benhayoun MK, Lebrec D, Benhamou JP. Pulmonary hypertension complicating portal hypertension: prevalence and relation to splanchnic hemodynamics. Gastroenterology 1991; 100: 520-528.

2. Kowalski HJ, Abelmann WH. The cardiac output in Laennec cirrhosis. J Clin Invest 1953; 32: 1025-1033.

3. Kontos HA, Shapiro W, Mauck HP, Patterson JL. General and regional circulatory alterations in cirrhosis of the liver. Am J Med 1964; 37: 526-535.

4. Murray JF, Dawson AM, Sherlock S. Circulatory changes in chronic liver disease. Am J Med 1958; 24: 258-267.

5. Campillo B, Bories PN, Benvenutti C, Dupeyron C. Serum and urinary nitrate levels in liver cirrhosis: endotoxinemia, renal function and hyperdynamic circulation. J Hepatol 1996; 24: 707-714.

6. Campillo B, Chabrier PE, Pelle G, et al. Inhibition of nitric oxide synthesis in the forearm arterial bed of patients with advanced cirrhosis. Hepatology 1995; 22: 1423-1429.

7. Rodriguez-Roisin R, Roca J, Agusti AGN, Mastai R, Wagner PD, Bosch J. Gas exchange and pulmonary vascular reactivity in patients with liver cirrhosis. Am Rev Respir Dis 1987; 135: 1085-1092.

8. Daoud FS, Reeves JT, Scaeffer JW. Failure of hypoxic vasoconstriction in patients with liver cirrhosis. J Clin Invest 1971; 51: 1076-1080.

9. Naeije R, Hallemans R, Mols P, Melot C. Hypoxic pulmonary vasoconstriction in liver cirrhosis. Chest 1981; 80: 570-574.

10. Naeije R, Melot C, Hallemans R, Mols P, Lejeune P. Pulmonary hemodynamics in liver cirrhosis. Semin Respir Med 1985; 7: 164-170.

11. Melot C, Naeije R, Dechamps P, Hallemans R, Lejeune P. Pulmonary and extrapulmonary contributors to hypoxemia in liver cirrhosis. Am Rev Respir Dis 1989; 139: 632-640.

12. Lunzer MR, Newman SP, Bernard AG, Maughani KK, Sherlock SP, Ginsburg J. Impaired cardiovascular responsiveness in liver disease. Lancet 1975; ii: 382-385.

13. Panos RJ, Backer SK. Mediators, cytokines, and growth factors in liver-lung interactions. Clin Chest Med 1996; 17: 151-169.

14. Sogni P, Moreau R, Gadano A, Lebrec D. The role of nitric oxide in the hyperdynamic circulatory syndrome associated with portal hypertension. J Hepatol 1995; 23: 218-224.

15. Lundberg JON, Weitzberg E, Lundberg JM, Alving K. Nitric oxide in exhaled air. Eur Respir J 1996; 9: 26712680.

16. Matsumoto A, Ogura K, Kakoki M, et al. Increased nitric oxide in the exhaled air of patients with decompensated liver cirrhosis. Ann Intern Med 1995; 123: 110-113.

17. Sogni P, Garnier P, Moreau R, Dall'Ava-Santucci J, Dinh-Xuan AT, Lebrec D. Endogenous pulmonary nitric oxide production measured from exhaled air is increased in patients with severe cirrhosis. J Hepatol 1995; 23: 471-474.

18. Cremona G, Higenbottam TW, Alexander G, et al. Elevated nitric oxide in patients with hepatopulmonary syndrome. Eur Respir J 1995; 8: 1883-1885.
19. Hori N, Okanoue T, Kashima K, et al. Endogenous nitric oxide production is augmented as the severity advances in patients with liver cirrhosis. Clin Exp Pharmacol Physiol 1996; 23: 30-35.

20. Rolla G, Brussino L, Colagrande P, et al. Exhaled nitric oxide and oxygenation abnormalities in hepatic cirrhosis. Hepatology 1997; 26: 842-847.

21. Albillos A, Rossi I, Martinez MV, Abreu L, Barrios C, Escartin P. Enhanced endothelium-dependent vasodilation in patients with cirrhosis. Am J Physiol 1995; 268: G459-G464.

22. Calver A, Harris A, Maxwell JD, Vallance P. Effect of local inhibition of nitric oxide synthesis on forearm arterial bed of patients with alcoholic cirrhosis. Clin Sci 1994; 86: 203-208.

23. Vallance P, Moncada S. Hyperdynamic circulation in liver cirrhosis: a role for nitric oxide? Lancet 1991; 337: 776779.

24. Guarner C, Soriano G, Tomas A, et al. Increased serum ni-trite and nitrate levels in patients with cirrhosis: relationship to endotoxinemia. Hepatology 1993; 18: 11391143.

25. Le Moine O, Soupison T, Sogni P, et al. Plasma endotoxin and tumor necrosis factor- $\alpha$ in the hyperkinetic state of cirrhosis. J Hepatol 1995; 22: 391-395.

26. Laffy G, Foschi M, Simoni A, et al. Increased production of nitric oxide by neutrophils and monocytes from patients with ascites and hyperdynamic circulation. Hepatology 1995; 22: 1666-1673.

27. Chang SW, Ohara N. Pulmonary circulatory dysfunction in rats with biliary cirrhosis: an animal model of the hepatopulmonary syndrome. Am Rev Respir Dis 1992; 145: 796-805.

28. Niederberger M, Martin PY, Ginès $\mathrm{P}$, et al. Normalization of nitric oxide production corrects arterial vasodilatation and hyperdynamic circulation in cirrhotic rats. Gastroenterology 1995; 109: 1624-1630.

29. Pilette C, Kirstetter P, Sogni P, Moreau R, Lebrec D. Dose-dependent effects of a nitric oxide biosynthesis inhibitor on hyperdynamic circulation in two models of portal hypertension in conscious rats. $J$ Gastroenterol Hepatol 1996; 11: 1-6.

30. Chabot F, Mestiri H, Dall'Ava-Santucci J, Lockhart A, Dinh-Xuan AT. Role of NO in the pulmonary hyporeactivity to phenylephrine in experimental biliary cirrhosis. Eur Respir J 1996; 9: 560-564.

31. Fallon MB, Abrams GA, Ifou Z, et al. The role of endothelial nitric oxide synthase in the pathogenesis of a rat model of hepatopulmonary syndrome. Gastroenterology 1997; 113: 606-614.

32. Weigert AL, Martin PY, Niederberger M, et al. Endothelium-dependent vascular hyporesponsiveness without detection of nitric oxide synthase induction in aortas of cirrhotic rats. Hepatology 1995; 22: 1856-1862.

33. Morales-Ruiz M, Jimenez W, Pierez-Sala D, et al. Increased nitric oxide synthase expression in arterial vessels of cirrhotic rats with ascites. Hepatology 1996; 24: 14811484.

34. El-Newihi HM, Kanji VK, Mihas AA. Activity of gastric mucosal nitric oxide synthase in portal hypertensive gastropathy. Am J Gastroenterology 1996; 91: 535-538.

35. Rich S, Dantzker DR, Ayres SM. Primary pulmonary hypertension: a national prospective study. Ann Intern Med 1987; 107: 216-223.

36. Castro M, Krowka MJ, Schroeder DR, et al. Frequency and clinical implications of increased pulmonary artery pressures in liver transplantation. Mayo Clin Proc 1996; 
71: 543-551.

37. Mandell SM, Groves BM. Pulmonary hypertension in liver disease. Clin Chest Med 1996; 17: 17-33.

38. McDonnel PJ, Toye PA, Hutchins GM. Primary pulmonary hypertension and cirrhosis: are they related? Am Rev Respir Dis 1983; 127: 437-441.

39. Tamara P, Garcia-Valdecasas JC, Beltran J, et al. Moderate primary pulmonary hypertension in patients undergoing liver transplantation. Anaesth Analg 1996; 83: 675-680.

40. Rubin LJ. Primary pulmonary hypertension. ACCP consensus statement. Chest 1993; 104: 236-250.

41. Brenot F, Simonneau G. Risks factor for primary pulmonary hypertension. In: Rubin LJ, Rich S, eds. Primary Pulmonary Hypertension. Lung Biology in Health and Diseases, Vol. 99. New York, Marcel Dekker, 1997; pp. 131-149.

42. Abenhaim L, Moride Y, Brenot F, et al. Appetite-suppressant drugs and the risk of primary pulmonary hypertension. N Engl J Med 1996; 335: 609-616.

43. Nichols WC, Koller DL, Slovis B, et al. Localization of the gene for familial primary pulmonary hypertension. Nat Genet 1997; 15: 277-280.

44. Osterud B, Bajaj MS, Bajaj SP. Sites of tissue factor pathway inhibitor and tissue factor expression under physiologic and pathologic conditions. Thomb Haemost 1995; 73: 873-875.

45. Brown SL, Lundgren CH, Nordt T, Fujii S. Stimulation of migration of human aortic smooth muscle cell by vitronectin: implications for atherosclerosis. Cardiovasc Res 1994; 28: 1815-1820.

46. Rabinovitch M. Mechanisms of pulmonary hypertension in chronic high flow states. In: Weir EK, Reeves JT, eds. Pulmonary Vascular Physiology and Pathophysiology. Lung Biology in Health and Diseases, Vol. 38. New York, Marcel Dekker, 1989; pp. 469-511.

47. Hervé P, Launay JM, Scrobohaci ML, et al. Increased plasma serotonin in patients with primary pulmonary hypertension. Am J Med 1995; 99: 249-254.

48. Hervé P, Drouet L, Dosquet C, Simonneau G, Launay JM, Duroux P. Primary pulmonary hypertension in a patient with a familial storage pool disease: role of serotonin. $A m$ J Med 1990; 89: 117-120.

49. Humbert M, Monti G, Brenot F, et al. Increased serum interleukin-1 and interleukin-6 concentrations in severe primary pulmonary hypertension. Am J Respir Crit Care Med 1995; 151: 1628-1631.

50. Fanburg B, Lee SL. A new role for an old molecule: serotonin. Am J Physiol 1997; 272: L795-L806.

51. Beaudry P, Hadengue A, Callebert J, et al. Blood and plasma 5-hydroxytryptamine levels in patients with cirrhosis. Hepatology 1994; 20: 800-803.

52. Ashmore RC, Rodman DM, Sato K, et al. Paradoxical constriction to platelets by arteries from rats with pulmonary hypertension. Am J Physiol 1991; 260: H1929H1934.

53. Sato K, Webb S, Tucker A, et al. Factors influencing the idiopathic development of pulmonary hypertension in the fawn hooded rat. Am Rev Respir Dis 1992; 145: 793-797.

54. Voelkel NF, Tuder RM, Weir EK. Pathophysiology of primary pulmonary hypertension: from physiology to molecular mechanisms. In: Rubin LJ, Rich S, eds. Primary Pulmonary Hypertension. Lung Biology in Health and Diseases, Vol. 99. New York, Marcel Dekker, 1997; pp. 83-129.

55. Isner JM, Pieczek A, Schainfield R, et al. Clinical evidence of angiogenesis after arterial gene transfer of phVGEF $_{165}$ in patients with ischemic limb. Lancet 1996;
348: $370-374$

56. Groves BM, Brundage BH, Elliot CG, et al. Pulmonary hypertension associated with hepatic cirrhosis. In: Fishman AP, ed. The Pulmonary Circulation: Normal and Abnormal. Philadelphia, PA, University of Pennsylvania Press, 1990; pp. 359-369.

57. Kneussl MP, Lang IM, Brenot FP. Medical management of primary pulmonary hypertension. Eur Respir J 1996; 9: 2401-2409.

58. Rubin LJ. Primary pulmonary hypertension. $N$ Engl $J$ Med 1997; 336: 111-117.

59. Kuo PC, Plotkin JS, Howell CD, Bartlett ST, Rubin LJ. Continuous infusion of epoprostenol for the treatment of portopulmonary hypertension. Transplantation 1997; 63: 604-606.

60. Castro M, Krowka MJ. Hepatopulmonary syndrome: a pulmonary vascular complication of liver disease. Clin Chest Med 1996; 17: 35-48.

61. Berthelot P, Walker JG, Sherlock S, Reid L. Arterial changes in the lungs in cirrhosis of the liver: lung spider naevi. N Engl J Med 1966; 274: 291-298.

62. Krowka MJ, Dickson ER, Cortese DA. Hepatopulmonary syndrome: clinical observations and lack of therapeutic response to somatostatine analogue. Chest 1993; 104: 515-521.

63. Agusti AGN, Roca J, Rodriguez-Roisin R. Mechanisms of gas exchange impairment in patients with liver cirrhosis. Clin Chest Med 1996; 17: 49-66.

64. Rodriguez-Roisin R, Agusti AGN, Roca J. The hepatopulmonary syndrome: new name, old complexities. Thorax 1992; 47: 897-902.

65. Crawford ABH, Regnis J, Laks L, Donnelly P, Engel LA, Young IH. Pulmonary vascular dilatation and diffusiondependent impairment of gas exchange in liver cirrhosis. Eur Respir J 1995; 8: 1913-1919.

66. Wagner PD. Impairment of gas exchange in cirrhosis. Eur Respir J 1995; 8: 1993-1995.

67. Vachiery F, Moreau R, Hadengue A, et al. Hypoxemia in patients with cirrhosis: relationship with liver failure and hemodynamic alterations. J Hepatol 1997; 27: 492495.

68. Rolla G, Bucca C, Brussino L. Methylene blue in the hepatopulmonary syndrome. N Engl J Med 1994; 331: 1098.

69. Fallon MB, Abrams GA, McGrath JW, Hou Z, Luo B. Common bile duct ligation in the rat: a model of intrapulmonary vasodilatation and hepatopulmonary syndrome. Am J Physiol 1997; 272: G779-G784.

70. Luo B, Abrams GA, Fallon MB. Endothelin-1: a potential mediator of intrapulmonary vasodilatation in a rat model of hepatopulmonary syndrome. Hepatology 1997; 26: A390.

71. Schraufnagel DE, Malik R, Goel V, Ohara N, Chang SW. Lung capillary changes in hepatic cirrhosis in rats. Am J Physiol 1997; 272: L139-L147.

72. Srivastava D, Preminger T, Lock JE, et al. Hepatic venous blood and the development of pulmonary arteriovenous malformations in congenital heart disease. Circulation 1995; 92: 1217-1222.

73. Shah MJ, Rychick J, Fogel MA, Murphy JD, Jacobs ML. Pulmonary arteriovenous malformations after superior cavopulmonary connection: resolution after inclusion of hepatic veins in the pulmonary circulation. Ann Thorac Surg 1997; 63: 960-963.

74. Graham K, Sonheimer H, Schaffer M. Resolution of cavopulmonary shunt-associated pulmonary arteriovenous malformation after heart transplantation. J Heart Lung Transplant 1997; 16: 1271-1274. 
75. Lamour JM, Hsu DT, Kichuk MR, et al. Regression of pulmonary arteriovenous malformations following heart transplantation. J Heart Lung Transplant 1997; 16: A71.

76. Lange PA, Stoller JK. The hepatopulmonary syndrome. Ann Intern Med 1995; 122: 521-529.

77. Krowka MJ, Cortese DA. Pulmonary aspect of liver disease and liver transplantation. Clin Chest Med 1989; 10: 593-616.

78. Vedrinne JM, Duperret S, Bizollon T, et al. Comparison of transesophageal and transthoracic contrast echocardiography for detection of an intapulmonary shunt in liver disease. Chest 1997; 111: 1236-1240.

79. Abrams GA, Jaffe CC, Hoffer PB, Binder HJ. Diagnostic utility of contrast echocardiography and lung perfusion scan in patients with hepatopulmonary syndrome. Gastroenterology 1995; 109: 1283-1288.

80. Krowka MJ, Porayko MK, Plevak DJ, et al. Hepatopulmonary syndrome with progressive hypoxemia as an indication for liver transplantation: case reports and literature review. Mayo Clin Proc 1997; 72: 44-53.

81. Poterucha JJ, Krowka MJ, Dickson ER, Cortese DA, Stanson AW, Krom RAF. Failure of hepatopulmonary syndrome to resolve after liver transplantation and successful treatment with embolotherapy. Hepatology 1995; 21: 96-100.

82. Cadranel JL, Milleron BJ, Cadranel JF, et al. Severe hypoxemia-associated intrapulmonary shunt in a patient with chronic liver disease: improvement after medical treatment. Am Rev Respir Dis 1992; 146: 526-527.

83. Battaglia SE, Pretto JJ, Irving LB, Jones RM, Angus PW. Resolution of gas exchange abnormalities and intrapulmonary shunting following liver transplantation. Hepatology 1997; 25: 1228-1232.

84. Krowka MJ. Hepatopulmonay syndrome versus portopulmonary hypertension: distinctions and dilemmas. Hepatology 1997; 25: 1282-1284.

85. Raffy O, Sleiman C, Vachiery F, et al. Refractory hypoxemia during liver cirrhosis: hepatopulmonary syndrome or "primary pulmonary hypertension". Am J Respir Crit Care Med 1996; 153: 1169-1171.

86. Dawson A, Elias DJ, Rubenson D, et al. Pulmonary hypertension developing after aglucerase therapy in two patients with type I Gaucher disease complicated by the hepatopulmonary syndrome. Ann Intern Med 1996; 125 : 901-904.

87. Tasaka S, Kanazawa M, Nakamura H, et al. An autopsied case of primary pulmonary hypertension complicated by hepatopulmonary syndrome. Nippon Kyobu Shikkan Gakkai Zasshi 1995; 33: 90-94.

88. Mandall MS, Krowka MJ. Formation of a national database on pulmonary hypertension and hepatopulmonary syndrome in chronic liver disease. Anesthesiology 1997; 87: 450-451. 